\title{
MESENCHYMAL STEM CELLS VERSUS COVID-19. CAN THEY WIN THE BATTLE?
}

Amra Ramovic Hamzagic ${ }^{1}$, Dragica Miloradovic ${ }^{2}$, Dragana Miloradovic ${ }^{2}$, Zeljko Ivosevic ${ }^{2}$ and Biljana Ljujic ${ }^{2 *}$ ${ }^{1}$ State University of Novi Pazar, Department of biomedical sciences, Novi Pazar, Serbia

${ }^{2}$ University of Kragujevac, Faculty of Medical Sciences, Department of Genetics, Kragujevac, Serbia

\section{MEZENIMSKE MATIČNE ĆELIJE PROTIV KOVIDA-19. MOGU LI DA POBEDE U BORBI?}

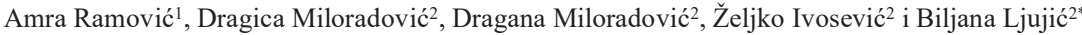

${ }^{1}$ Drzavni Univerzitet u Novom Pazaru, Katedra za biomedicinske nauke, Novi Pazar, Srbija

${ }^{2}$ Univerzitet u Kragujevcu, Fakultet medicinskih nauka, Katedra za genetiku, Kragujevac, Srbija

\begin{abstract}
Mesenchymal stem cells (MSCs) are multipotent stem cells with numerous features potentially useful in various pathologies. It has been shown that MSCs have regenerative potential due to modulation of immune system response, inflammation diminishing, trans differentiation into various types of cells, proangiogenetic and anti fibrotic influence. Besides all of these traits, MSCs posses anti viral capacity and have been further employed in clinical trails since last year. Here, we revised immunomodulatory, biological and antiviral traits of MSCs, but also pathogenesis of Covid-19 and it's impact on immune system. Conspicuously, there is a growing number of studies examining effect of MSCs in patients suffering from Covid-19 pneumonia and ARDS. Since MSCs are in theory capable of healing lung injury and inflammation, here we discuss hypothesis, pros and cons of MSCs treatment in Covid-19 patients. Finally, we debate if MSCs based therapy can be promising tool for Covid-19 lung pathologies.
\end{abstract}

Keywords: mesenchymal stem cells, inflammation, covid-19, pneumonia, ARDS.

\section{SAŽETAK}

Mezenhimske matične ćelije su multipotentne matične ćelije sa brojnim svojstvima koja mogu da budu potencijalno korisna $u$ različitim bolestima. Pokazno je da mezenhimske matične ćelije imaju regenerativni potencijal zbog mogućnosti da modifikuju $i$ munski odgovor, smanje zapaljenje, da se transdiferentuju u različite vrste ćelija, stimulišu angiogenezu i smanje fibrozu. Osim navedenih karakteristika, mezenhimske matične ćelije poseduju $i$ antivirusna svojstva i sve više su korišćene u kliničkim studijama od prošle godine. U ovom radu smo revidirali imunomodulatorna, biološka i anivirusna svojstva mezenhimskih matičnih ćelija, ali takođe i patogenezu i uticaj Kovida-19 na imunski sistem. Postoji značajan porast studija koje ispituju dejstvo mezehimskih matičnih ćelija na pacijente sa zapaljenjem pluća i akutnim respiratornim distres sindromom koji su uzrokovani Kovid-19 virusom. S obzirom da mezehimske matične ćelije u teoriji mogu da leče oštećenja i inflamaciju pluća, ovde razmatramo hipoteze, prednosti i nedostatke primene mezenhimskih matičnih ćelija kod Kovid-19 pacijenata. Na kraju, raspravljamo da li terapija mezenhimskim matičnim ćelijama može da bude obećavajući terapijski izbor za plućna oboljenja uzrokovana Kovid-19 virusom.

Ključne reči: mezenhimske matične ćelije, upala, covid-19, upala pluća, ARDS.

\section{ABBREVIATIONS}

ACE2 - Angiotensin-converting enzyme 2

AngII - Angiotensin 2 pathway

ARDS - Acute respiratory distress syndrome

AT-MSCs - Adipose tissue derived mesenchymal stem cells

BM-MSC - Bone marrow derived mesenchymal stem cells

CCL2 - C-C Motif Chemokine Ligand 2)

COPD - Chronic Obstructive Pulmonary Disease

CRP - C-reactive protein

CVDs - Cardiovascular disease

DCs- Dendritic cells

FGF7- Fibroblast Growth Factor 7
G-CSF - Alpha granulocyte-colony stimulating factor

GM-CSF- Granulocyte-macrophage colony-stimulating factor

GVHD - Graft- versus host disease

HCoV-19- Human coronavirus 2019

hESC - Human embryonic stem cell

HGF - Hepatic growth factor

hiPSC - Human induced pluripotent stem cells

HLA-G- Human leukocyte antigen-G

HO- Heterotopic ossification

HO-1- Hemeoxygenase-1

hWJCs - Wharton Jelly's MSCs 
IDO - Indolamine 2,3-dioxygenase IL-10,

IFI6 - Interferon Alpha Inducible Protein 6

IFITM - Interferon-inducible transmembrane

IFNAR2 - Interferon Alpha And Beta Receptor Subunit 2

IL-1Ra - Interleukin 1 receptor antagonist

IL-6 Amp - Interleukin-6 amplifier

IL-6 - Interleukin-6

ISG - Interferon stimulated genes

KGF - Keratinocyte growth factor

LIF - Leukocyte inhibitory factor

MCP-1- Monocyte chemoattractant protein-1

MERS - Middle East respiratory syndrome

MIP1A - Macrophage inflammatory protein 1

MODS - Multiple organ dysfunction syndrome

MSC-EV- Mesenchymal stem cell derived extracellular vesicles

MSCs -Mesenchymal stem cells

MT1G -Metallothionein 1G

NETs -Neutrophil extracellular traps

NO - Nitric oxide

p21/CDKN1A - p21 Cyclin Dependent Kinase Inhibitor $1 \mathrm{~A}$
PD - programmed cell death

PGE2 - Prostaglandin E2

PMAIP1 - Phorbol-12-Myristate-13-Acetate-Induced Protein 1

SARS - Severe acute respiratory syndrome

SARS-CoV-2- SARS coronavirus 2

SAT- Spermidine/spermine N(1)-acetyltransferase

SERPINE1 - Serpin family E member 1

sIL-6Ra - Interleukin-6a

SARS-CoV-2S - spike glycoprotein

TGF-b - Transforming growth factor-b ,

TLRs - Toll like receptors

TMPRSS2 - Transmembrane protease serine 2

TNF- $\alpha$ - Tumor necrosis factor- $\alpha$

Tregs - Regullatory T cells

TSG-6 - Tumor necrosis factor a-stimulated gene 6

UCB-MSCs - Umbilical chord blood derived mesenchymal stem cells

VEGF - Vascular endothelial growth factor

WHO -World Health Organization

\section{INTRODUCTION}

Mesenchymal stem cells (MSCs) are adult multipotent stem cells with ability to self renew and can be isolated from various tissues (1). MSCs are defined by three norms- adherence to culture flasks; expression of cluster of differentiation CD105, CD73 and CD90 but also absence of CD45, CD34, CD11b, CD14, CD79a, CD31 and MHC class II molecule. Additionally, MSCs can differentiate into different types of tissues (2) therefore representing an excellent tool for regenerative medicine. MSCs can migrate to the sites of injury and modulate immune response (3). This trait, among others, makes MSCs an excellent choice for immune-mediated diseases. Immediately after engraftment, MSCs interact with both, innate and adaptive immune system in two ways; by paracrine manner and by PD receptor interaction. Paracrine manner includes release of numerous soluble factors- transforming growth factor-b (TGF-b), hepatic growth factor (HGF), nitric oxide (NO), indolamine 2,3-dioxygenase (IDO), IL-10, IL-6, leukocyte inhibitory factor (LIF), IL-1 receptor antagonist (IL-1Ra), galectins, tumor necrosis factor a-stimulated gene 6 (TSG-6), human leukocyte antigen-G (HLA-G), hemeoxygenase-1 (HO-1), and prostaglandin E2 (PGE2) hence emphasizing it's immunosupressive potential. MSCs influence immune response by interaction with crucial inflammatory cells, specifically, MSCs abolish production and spur of pro-inflammatory M1 macrophages and provoke their alteration in M2 phenotype (4). Also, MSCs can negatively impact dendritic cells DCs in terms of their growth and secretion of various cytokines, which eventually leads to diminished inflammation due to T cells inhibition (5-7). MSCs can diminish generation of Th1 and Th17 cytokines, but also enhance Th2 cytokines generation (19-21). Proliferation of Th1 and Th17 cells can be suppressed by MSCs, but also, MSCs can add to the number of Tregs, and in that manner can have immunosupressive and anti-inflammatory effect (8). In spite of that, MSCs can adopt pro-inflammatory phenotype as well, which is determined by the environmental conditions (9). Actually, low levels of pro inflammatory cytokines promote pro-inflammatory phenotype of MSCs and vice versa (9). This balance of MSCs' phenotype is determined by Toll like receptors (TLRs) (10) that also represent main receptor for virus recognition (11-13). Important element of MSCs mediated immunomodulation are exosomes $(14,15)$ and various secretomes $(16,17)$. For instance, Let-7, miR-34a, miR-146a and miR200b/c are known to be involved in proinflammatory metabolic pathways $(18,19)$. Let7 has been involved in the suppression of posttranscriptional regulation of IL- 6 secretion and downregulates TLR4 signal $(20-22)$. Also, miR-34a and miR-146 turns out to have a critical role in regulation of NF-kB cascade, possibly aiming upstream elements at the time of $\mathrm{T}$ cell stimulation $(23,24)$. Eventually, miR-200b/c presumably diminishes complement tentative cytolysis, induced by C5b-9 coupling, since suppression of miR-200c increased MSC demise (25). These outcomes propose the anti inflammatory and cytoprotective features of miRNAs from MSC-EV, confirming that MSCs secretomes promote tissue regeneration by neoangiogenesis, apoptosis inhibition and fibrosis inhibition (26-32), which can be beneficial in numerous pathologies especially those with inflammatory component in pathogenesis. 


\section{MSCs sources}

Bone marrow, adipose tissue, umbilical cord and dental pulp are suggested as convenient sources of MSCs, yet it is not completely elucidated which source of MSCs is optimal $(38,39)$. BM-MSCs are characterized by easy acquisition, rapid expansion in vitro, minimum immunologic rejection, protracted standing post-transplatationally in the host, preservation of capacity to differentiate subsequently to repetitive passages as well as simplicity of transplantation $(40,41)$. Anyway, the acquisition of BM-MSCs is complicated process and also, size and longevity of BM-MSCs diminishes by ageing $(42,43)$. So, to bypass such obstacles, alternative sources for MSCs isolation are implied $(12,13)$. Umbilical cord blood and adipose tissue have been proposed as an alternate source for isolation and therapeutic employment of MSCs regarding its larger proliferative potential, high cell yields and ease of harvesting $(44,45)$. BM-MSCs, UCB-MSCs and AT-MSCs all have similar morphological as well as operational traits (11). In the context of current pandemic Covid-19, and the entire inflammatory response caused by cytokine storm, as it will be further elaborated in this review, adequate MSCs source should be discussed so that optimal MSCs could be employed in therapy. Since the virus enters the cells through target ACE2 receptor, it is crucial to decide whether MSCs from any of these sources express ACE2 receptor, and therefore is susceptible to Covid-19 infection. Recent study showed that ACE2 is highly expressed in adult bone marrow, adipose tissue or umbilical cord-derived MSC. Distinguishing from placental derived MSCs together with human embryonic stem cell (hESC) or human induced pluripotent stem cells (hiPSC) that express low levels of ACE2 receptor (46). These outcomes should be further taken into consideration when determining on the optimal source of MSC therapy.

\section{Cytokine storm in Covid-19}

In December 2019, non typical infectious respiratory syndrome of idiopathic cause was recognised in Wuhan, China. Having already met with manifestations of (SARS) in 2003, Chinese scientific and medical department could identify a new coronavirus, SARS coronavirus 2 (SARS-CoV-2) as the pathogen (47). SARS-CoV-2 was easily and quickly spread all across the globe, leading to high morbidity and mortality. In order to prevent further spread of the virus, lock-down and other quarantine measures were enforced. Ease of spreading, high morbidity and mortality rate, changed the portrait of this pathogen, so on March 11, 2020, the World Health Organization (WHO) declared COVID-19 a global pandemic. The COVID-19 is clinically heterogeneous, patients may be asymptomatic or have light, moderate, severe or critical clinical traits. Symptoms of COVID-19 may vary, but most common include fever, headache, malaise, cough, bone pain, myalgias, anosmia, impaired taste and respiratory distress. Similar to SARS in 2003, this infectious disease leads to a high probability of ICU admission and mortality $(48,49)$. The pathogenesis of SARS-CoV-2 has been explained by the interaction and binding of the virus spike glycoprotein (SARS$\mathrm{CoV}-2 \mathrm{~S}$ ) to the angiotensin-converting enzyme-related carboxypeptidase (ACE2) on the target cell surface. After binding, spike protein is activated by the cellular transmembrane protease serine 2 (TMPRSS2) which enables the virus to enter the host cell (50), leading to complex over activated inflammation and immune response, known as cytokine storm. The term "cytokine storm" was first established in 1993. to depict a graft versus host disease, and defines as the rapid and sudden efflux of a large number of cytokines that happens as a result of the immune system' s overactivation by some stimuli (infection, drugs, etc.), begin locally and disseminate systemically, triggering collateral detriment in tissues $(51,52)$. It is elucidated that cytokine storm is linked with the exacerbation of various infectious diseases, such as severe acute respiratory syndrome (SARS), Middle East respiratory syndrome (MERS), and with the severity of COVID19 (53). However, it was reported that cytokine storm is one of the main causes of a severe form of the disease in COVID19 patients and dying, and is associated with thrombosis, massive mononuclear cell infiltration in multiple organs, and high levels of circulating cytokines (54). Notwithstanding that the specific dysregulated molecular causes are still not understood, it is assumed that cytokine storm is caused by disbalance in the regulation of the immune system (i.e., increment in immune cell activation via TLR or another mechanism, decreasing in anti-inflammatory response, etc.) (51). The immune response is being provoked by SARS-CoV-2 entering respiratory epithelial cells and is accompanied by inflammatory cytokine production and weak interferon (IFN) response. Cytokine storm occurs as a result of activation of pro-inflammatory Th1 cells and intermediate CD14+ CD16+ monocytes, macrophages, and neutrophils infiltration into the lung tissue (54). Specifically, pathogenic Th1 cells that produce pro-inflammatory cytokines, such as granulocyte-macrophage colony-stimulating factor (GM-CSF) and interleukin-6 (IL-6) can be activated by SARS-CoV-2 very fast. After that, GM-CSF further activates CD14+ CD16+ inflammatory monocytes to secrete immense amounts of IL-6 and tumor necrosis factor- $\alpha$ (TNF- $\alpha)$ (55). Neutrophil extracellular traps (NETs), weak IFN- $\gamma$ induction, and membrane-bound immune receptors (e.g., Fc and Toll-like receptors), might be some of the causes for massive cytokine release $(53,54)$. One of the possible mechanisms of the cytokine storm is induced by the angiotensin 2 (AngII) pathway, where SARS-CoV-2 triggers NF- $\kappa \mathrm{B}$. ACE2 on the cell surface is occupied by SARS-CoV-2, which results in decreasing in ACE2 expression and an increase in AngII. Also, AngII-angiotensin receptor type 1 (AngII-AT1R) axis can induce TNF- $\alpha$ and the soluble form of IL-6Ra (sIL-6Ra). IL-6 binds to sIL-6R through gp130 to form the IL-6-sIL-6R complex, which can trigger STAT3 in non-immune cells. Both NF- $\kappa \mathrm{B}$ and STAT3 are able for activation of the IL-6 amplifier (IL-6 Amp) to induce various pro-inflammatory cytokines and chemokines, such as IL-8, and IL-6, vascular endothelial growth factor (VEGF), monocyte chemoattractant protein-1 (MCP-1) $(56,57)$. Some studies have been demonstrated that levels of IL-1 $\beta$, IL-2, IL-6, IL-7, IL-8, IL-12, inducible protein 10 (IP-10), MCP-1, TNF- $\alpha$, macrophage inflammatory protein 1 alpha (MIP1A), granulocyte-colony stimulating factor (G-CSF), and IFN- $\gamma$ were increased, though levels of 
the Th2 cytokine IL-4 were low in patients with severe COVID-19 $(58,59,60)$. Other studies showed that the level of CD4+ cells and CD8+ cells was reduced constantly, but neutrophil counts were elevated in patients with a severe form of COVID-19 comparing with mild patients (60). Because of the rapid evolution of the cytokine storm, critically ill COVID-19 patients develop acute respiratory distress syndrome (ARDS) (61). ARDS is described as a multi-factorial syndrome of severe lung injury whose main characteristics are: hypoxemia, pulmonary oedema, diffuse alveolar damage and multiple organ failure. Lungs are not able to provide sufficient oxygen saturation to the alveolar spaces and respiratory support may be required (62). Yet, there are paradoxical outcomes in terms of SARS-CoV-2 positive Chronic Obstructive Pulmonary Disease (COPD) patients. Actually, most of COPD patients did not develop critical symptoms, which is contradictory, due to the fact that pulmonary co morbidity elevates chances of ARDS development and fatal outcome $(63,64)$. It is assumed that key role in this "protection" plays IL-6. Covid-19-related pneumonia is caused by inflammasomes activation and secretion of IL-1, TNF and IL-6, making IL-6 crucial in ARDS development. IL-6 coordinates the cytokine storm resulting in an immune hyper-reaction and in the inflammatory injury of the pulmonary tissue (65). This is in line with a meta-analysis that emphasized high levels IL6 in the severe forms of Covid-19 (66). Moderately-elevated concentrations of IL- 6 found in moderate COPD patients has protective roles against the decay of Covid-19, explaining therefore their better prognosis. Eventually, the drug Tocilizumab, a monoclonal antibody that blocks the IL-6 receptor, is currently used to treat Covid-19 in hospitals (67). These outcomes, lead to conclusion that Tocilizumab must be utilised only in patients with an current cytokine storm, or else, it's usage may be damaging.

\section{MSCs' antiviral traits against Covid-19}

Luckily, MSCs are insusceptible to virus infections due to IFN-stimulated genes (ISG), that can impact every of step of viral cycle (68-70). Specifically, PMAIP1, ISG15, IFI6, IFITM, SAT1, p21/CDKN1A, SERPINE1 and CCL2 are ISGs that being expressed in MSCs are shown to halt numerous viral pathogens, but most importantly SARS (69). Team of researches made a list of ISGs constitutively expressed by human MSC and afterwards set up by IFITM1, IFI6, CCL2, ISG15, SAT1 and PMAIP1. In attendance of IFN- $\gamma$ there was an induction of non-constitutive ISGs, as well as MT1G, CD74, SERPING1, IFNAR2 and MT1X (68). MSCs have this great ability to switch to non-constitutive ISGs up regulation in order to better fight viruses, which can be advantageous in regards to respiratory infections (68). One of the most crucial ISGs is IDO, which not just that have immunomodulatory properties, but also inhibits viral protein bio synthesis (71). These anti viral features, besides familiar MSCs' immunomodulatory, antiinflammatory, neoangiogenic, regenerative and multipotent potential, definitely make MSCs potent and competent player in a harsh battle against Covid19.

\section{MSCs as a tool for Therapeutic Applications in Covid-19}

Since SARS-CoV-2 and COVID-19 first and foremost affect lungs, leading to ARDS, pneumonia and MODS consecutively, plus the fact that MSCs entrap in lungs, traits of MSCs residing in lungs should be thoroughly observed as therapeutic tool for SARS-CoV-2. It is shown that lung residing MSCs promote regeneration and tissue repair (72). Lung residing MSCs are positioned perivasculary and express CD73 which in turn promotes expression of anti-inflammatory genes in MF and vice versa (72). Again, exhibition of this marker is flexible and differ depending on the cell surrounding conditions, and testify how MSCs are sensitive to inflammatory response (73). MSCs respond by production of soluble factors, specifically when in lungs- MSCs secrete FGF7 (or KGF) leading to normalization of alveolar clearance (74). Various proteomic and transcriptomic analyses displayed that lung MSCs affect signal pathways in regards to up regulation of $\mathrm{Wnt} / \beta$-catenin and down-regulation of NF- $\kappa \mathrm{B}$ signaling, leading to diminished TNF- $\alpha$ production and eventually to fibrosis reduction $(75,76,77)$. MSCs displayed remedial effect in model of ARDS by stimulating surfactant secretion, differentiating into pulmonary endothelial cells and alveolar epithelial cells (78). Hence, most important are exactly these effect in regards to SARS-CoV-2-cytokine storm and ARDS $(79,80)$, which has already been elaborated in preclinical and clinical studies $(81,82)$.

\section{Clinical applications of MSCs in COVID-19}

Most recent study revised outcomes of MSCs applied in patients with ARDS and Covid-19 related conditions (83). When it comes to ARDS, highlights should be noted; patients with ARDS received BM-MSCs in dose of 10 million cells $/ \mathrm{kg}$. It is found no MSCs related adverse effects, except for, three patients who died in next weeks after treatment. Yet, for one who died from multiple spleen, brain and kidney embolic infarctions, it is confirmed by MRI that these changes were present prior to MSC administration (84) suggesting MSCs administration as safe. This study was the first phase of research, that was extended by Matthay et al. (85), and included much larger group of moderate to severe ARDS patients who received intravenously same dosage of human bone-marrow-derived MSCs. This study suggested no infusion-related haemodynamic or respiratory complications, even though higher numerically mortality and severity scores were observed in patients who received MSCs comparing to placebo group, but this difference was not statistically significant. Most important is the finding that showed direct impact of MSCs viability on angiopoetin 2 plasma concentrations, leading to drastic decrease of angiopoetin 2 concentrations, 6h after MSCs infusion which can be beneficial in ARDS. This study is planned to be continued, so more consistent and clear data could enlighten previous conclusions. In spite of insufficient and limited data in regards to clinical outcomes from patients that received MSCs therapy to fight Covid-19 respiratory disease, certain clinical trials emerged and propose MSCs as safe, beneficial and with no detrimental adverse effects $(86,87)$. Patients in China, on March in 2020, 
with severe COVID-19 pneumonia, were treated with MSCs, intravenously. In this study for the first time it is showed that MSCs are ACE2- and TMPRSS2- and that MSCs secrete anti-inflammatory factors to prevent the cytokine stormhence displaying that MSCs have natural immunity to the $\mathrm{HCoV}-19$. This MSCs therapy improved vital condition of patients, reduced level of inflammatory cytokines and chemokines so less mononuclear/ macrophages were attracted to injured lung tissue. At the same time bigger number of regulatory DCs were directed to the inflammatory tissue niche. In addition, they noted enhanced levels of IL-10 and VEGF, decreased C-reactive protein and TNF- $\alpha$ levels (80). Among these data most important was the observation of lack of overactivated cytokine-secreting immune cells CXCR3+ CD4+ T cells, CXCR3 + CD8+ T cells and CXCR3+ NK cells (80), which in summary can explain lung regeneration and improvement in critical patients. Later on, in June, a detailed review by Rajarshi stated MSCs therapy in COVID-19 patients as justified and advantageous (88). Other study examined therapeutic potential of Wharton Jelly's MSCs (hWJCs) delivered intravenously in COVID-19 positive critically ill patient with pneumonia and diabetes. After his vital parameters stabilized, he received hWJCs intravenously. After hWJC adoptive transfer, there were no adverse effects whereas level of serum CRP and inflammatory factors (IL-6 and TNF- $\alpha$ ) were drastically decreased, and vital parameters of the patient improved. Plus the level of CD3+, CD4+ and CD8 $+\mathrm{T}$ cell were significantly increased after intravenous injection of hWJCs (89). This is the first study of this kind, and though encouraging and promising, should be elaborated and further examined with much bigger group of patients. These preliminary clinical records lead to conclusion that MSCs alone or combined with other therapeutics could enhance the chances of survival and improve overall health condition in Covid-19 patients $(80,90)$. One study examined exosomes (ExoFloTM) derived from allogeneic BM-MSCs as treatment for severe COVID-19 (91). 24 SARS-CoV-2 PCR positive patients received $15 \mathrm{~mL}$ dose of ExoFlo intravenously and were observed in regards to safety and effectiveness.
There were no any side effects of ExoFlo treatment 72 hours after treatment. $83 \%$ of the patients survived, $71 \%$ of patients cured; $13 \%$ stayed in critical though stable condition; $16 \%$ passed away of causes unconnected to the therapy. On the whole, after treatment, patients' clinical condition and oxygenation improved. Additionally, there were enhancements in absolute neutrophil number and lymphopenia. Also, there was significant diminishing of C-reactive protein (CRP), Ferritin and D-dimer, confirming therefore beneficial effect of ExoFlo on inflammatory response. Having in mind such data, ExoFlo could be a prommising tool of Covid-19 related pathology, due to it's safety, ability to halt inflammation, stabilize immune response and oxygenation. In spite of that, further research with bigger group of patients with similar results could guarantee ExoFlo as secure therapeutic approach.

\section{Ongoing Clinical trials MSC-Based Therapies for COVID-19}

In order to summarize ongoing MSC-based therapies in patients suffering from Covid-19 worldwide ClinicalTrials.gov database was analysed. There are 68 studies that include MSCs treatment in various Covid-19 related conditions-Pneumonia and ARDS. Most of these studies are randomised and open-label studies and in early phase (phase I, I/II, II). Specifically, 29 of the studies are currently recruiting, yet 26 are not recruiting yet. There are 8 completed studies, while there are 3 enrolling and 1 study is withdrawn. Most of the studies utilised BM-MSC, UC-MSC, WJ MSC, AT-MSCs. However, there are fewer studies that utilised allogeneic dental pulp MSCs, placenta-derived MSCs, stromal MSCs, MSC derived exosomes and secretomes. Most of the studies follow basic protocols of disease severity assessment such as inflammatory cytokine profile (TNF- $\alpha$, IL-6 and IL10), vital parameters and pulmonary function assessment. Studies groups include both, males and females varying in age. All of these data are summarized in Table 1.

Table 1. MSC-based ongoing clinical trials for Covid-19 infection diseases

\begin{tabular}{|ll|}
\hline $\begin{array}{l}\text { Study Name: } \\
\text { Status: }\end{array}$ & Mesenchymal Stem Cell Infusion for COVID-19 Infection (NCT04444271) \\
Treatment: & Recruiting (Phase II) \\
\hline Study Name: & MSC \\
& COVID-19 (NCT04416139) \\
Status: & Recruiting (Phase II) \\
Treatment: & MSC \\
\hline
\end{tabular}




\begin{tabular}{|ll|}
\hline Study Name: & $\begin{array}{l}\text { Mesenchymal Stem Cells Therapy in Patients With COVID-19 Pneumonia } \\
(\text { NCT04713878) }\end{array}$ \\
Status: & Completed \\
Treatment: & MSC \\
\hline
\end{tabular}

\begin{tabular}{|ll|}
\hline Study Name: & Safety and Efficacy of Mesenchymal Stem Cells in the Management of Severe \\
& COVID-19 Pneumonia (NCT04429763) \\
Status: & Not yet recruiting (Phase II) \\
Treatment: & UC-MSC \\
\hline
\end{tabular}

\begin{tabular}{|ll|}
\hline Study Name: & Cord Blood-Derived Mesenchymal Stem Cells for the Treatment of COVID-19 \\
& Related Acute Respiratory Distress Syndrome (NCT04565665) \\
Status: & Recruiting (Phase I) \\
Treatment: & MSC \\
\hline
\end{tabular}

\begin{tabular}{|ll|}
\hline Study Name: & $\begin{array}{l}\text { NestaCell } \\
\text { (NCT04315987) }\end{array}$ \\
Status: & Not yet recruiting (Phase II) \\
Treatment: & MSCs (NestaCell®)
\end{tabular}

\begin{tabular}{|ll|}
\hline Study Name: & Mesenchymal Stem Cells in Patients Diagnosed With COVID-19 (NCT04611256) \\
Status: & Recruiting(Phase I) \\
Treatment: & MSC \\
\hline
\end{tabular}

\begin{tabular}{|ll|}
\hline Study Name: & Use of Mesenchymal Stem Cells in Acute Respiratory Distress Syndrome Caused \\
& by COVID-19 (NCT04456361) \\
Status: & Early Phase I \\
Treatment: & WJ-MSC \\
\hline
\end{tabular}

\begin{tabular}{|ll|}
\hline Study Name: & Efficacy of Infusions of MSC From Wharton Jelly in the SARS-Cov-2 (COVID- \\
& 19) Related Acute Respiratory Distress Syndrome (NCT04625738) \\
Status: & Not yet recruiting (Phase II) \\
Treatment: & WJ-MSC \\
\hline
\end{tabular}

\begin{tabular}{|ll|}
\hline Study Name: & Mesenchymal Stem Cell Treatment for Pneumonia Patients Infected With COVID- \\
& 19 (NCT04252118) \\
Status: & Recruiting(Phase I) \\
Treatment: & MSCs \\
\hline
\end{tabular}

\begin{tabular}{|ll|}
\hline Study Name: & Clinical Trial of Allogeneic Mesenchymal Cells From Umbilical Cord Tissue in \\
& Patients With COVID-19 (NCT04366271) \\
Status: & Recruiting (Phase II) \\
Treatment: & WJ-MSC \\
\hline
\end{tabular}

\begin{tabular}{|ll|}
\hline Study Name: & Treatment of COVID-19 Patients Using Wharton's Jelly-Mesenchymal Stem Cells \\
& (NCT04313322) \\
Status: & Recruiting(Phase I) \\
Treatment: & Use of Stem Cells for COVID-19 Treatment \\
& WJ-MSCs \\
\hline
\end{tabular}




\begin{tabular}{|ll|}
\hline Study Name: & Clinical Trial to Assess the Safety and Efficacy of Intravenous Administration of \\
& $\begin{array}{l}\text { Allogeneic Adult Mesenchymal Stem Cells of Expanded Adipose Tissue in Patients } \\
\text { With Severe Pneumonia Due to COVID-19 (NCT04366323) }\end{array}$ \\
Status: & Active, not recruiting (Phase II) \\
Treatment: & AT-MSC \\
\hline
\end{tabular}

\begin{tabular}{|ll|}
\hline Study Name: & Treatment of Severe COVID-19 Patients Using Secretome of Hypoxia- \\
& Mesenchymal Stem Cells in Indonesia (NCT04753476) \\
Status: & Recruiting (Phase II) \\
Treatment: & Injection of Secretome-MSCs \\
\hline
\end{tabular}

\begin{tabular}{|ll|}
\hline Study Name: & Safety and Efficacy Study of Allogeneic Human Dental Pulp Mesenchymal Stem \\
& Cells to Treat Severe COVID-19 Patients (NCT04336254) \\
Status: & Recruiting (Phase I, II) \\
Treatment: & Allogeneic human dental pulp stem cells (BSH BTC \& Utooth BTC) \\
\hline
\end{tabular}

\begin{tabular}{|ll|}
\hline Study Name: & $\begin{array}{l}\text { Bone Marrow-Derived Mesenchymal Stem Cell Treatment for Severe Patients With } \\
\text { Coronavirus Disease 2019 (COVID-19) (NCT04346368) }\end{array}$ \\
Status: & Not yet recruiting (Phase I, II) \\
Treatment: & BM-MSCs \\
\hline
\end{tabular}

\begin{tabular}{|ll|}
\hline Study Name: & Treatment With Human Umbilical Cord-derived Mesenchymal Stem Cells for \\
& Severe Corona Virus Disease 2019 (COVID-19) (NCT04288102) \\
Status: & Completed (Phase II) \\
Treatment: & UC-MSCs \\
\hline
\end{tabular}

\begin{tabular}{|ll|}
\hline Study Name: & Study to Evaluate the Efficacy and Safety of AstroStem-V in Treatment of COVID- \\
& 19 Pneumonia (NCT04527224) \\
Status: & Not yet recruiting (Phase I, II) \\
Treatment: & Adipose tissue-derived mesenchymal stem cells (AstroStem-V) \\
\hline
\end{tabular}

\begin{tabular}{|ll|}
\hline Study Name: & Regenerative Medicine for COVID-19 and Flu-Elicited ARDS Using Longeveron \\
& Mesenchymal Stem Cells (LMSCs) (NCT04629105) \\
Status: & Recruiting (Phase I) \\
Treatment: & Longeveron Mesenchymal Stem Cells (LMSCs) \\
\hline
\end{tabular}

\begin{tabular}{|ll|}
\hline Study Name: & Study of Human Umbilical Cord Mesenchymal Stem Cells in the Treatment of \\
& Severe COVID-19 (NCT04273646) \\
Status: & Not yet recruiting \\
Treatment: & UC-MSCs \\
\hline
\end{tabular}

\begin{tabular}{|ll|}
\hline Study Name: & Study of Intravenous Administration of Allogeneic Adipose-Derived Mesenchymal \\
& Stem Cells for COVID-19-Induced Acute Respiratory Distress (NCT04728698) \\
Status: & Not yet recruiting (Phase II) \\
Treatment: & COVI-MSC \\
\hline
\end{tabular}

\begin{tabular}{|ll|}
\hline Study Name: & $\begin{array}{l}\text { A Randomized, Double-Blind, Placebo-Controlled Clinical Trial to Determine the } \\
\text { Safety and Efficacy of Hope Biosciences Allogeneic Mesenchymal Stem Cell } \\
\\
\text { Therapy (HB-adMSCs) to Provide Protection Against COVID-19 (NCT04348435) }\end{array}$ \\
Status: & Enrolling by invitation (Phase II) \\
Treatment: & HB-adMSCs \\
\hline
\end{tabular}




\begin{tabular}{|ll|}
\hline Study Name: & Treatment of Covid-19 Associated Pneumonia With Allogenic Pooled Olfactory \\
& Mucosa-derived Mesenchymal Stem Cells (NCT04382547) \\
Status: & Enrolling by invitation (Phase I,II) \\
Treatment: & Allogenic pooled olfactory mucosa-derived MSC \\
\hline
\end{tabular}

\begin{tabular}{|ll|}
\hline Study Name: & Clinical Research of Human Mesenchymal Stem Cells in the Treatment of COVID- \\
& 19 Pneumonia (NCT04339660) \\
Status: & Recruiting(Phase I,II) \\
Treatment: & UC-MSCs \\
\hline
\end{tabular}

\begin{tabular}{|ll|}
\hline Study Name: & Expanded Access Protocol on Bone Marrow Mesenchymal Stem Cell Derived \\
& Extracellular Vesicle Infusion Treatment for Patients With COVID-19 Associated \\
& ARDS (NCT04657458) \\
Status: & Phase I \\
Treatment: & BM-MSC Derived Extracellular Vesicles Infusion Treatment \\
\hline
\end{tabular}

\begin{tabular}{|ll|}
\hline Study Name: & Mesenchymal Stem Cell Therapy for SARS-CoV-2-related Acute Respiratory \\
& Distress Syndrome \\
& (NCT04366063) \\
Status: & Recruiting(Phase II,III) \\
Treatment: & Cell therapy protocol \\
\hline
\end{tabular}

\begin{tabular}{|ll|}
\hline Study Name: & Autologous Adipose-derived Stem Cells (AdMSCs) for COVID-19 \\
& (NCT04428801) \\
Status: & Not yet recruiting(Phase II) \\
Treatment: & Autologous adipose-derived stem cells \\
\hline
\end{tabular}

\begin{tabular}{|ll|}
\hline Study Name: & Administration of Allogenic UC-MSCs as Adjuvant Therapy for Critically-Ill \\
& COVID-19 Patients (NCT04457609) \\
Status: & Recruiting (Phase I) \\
Treatment: & Oseltamivir| UC-MSC \\
\hline
\end{tabular}

\begin{tabular}{|ll|}
\hline Study Name: & A Clinical Trial to Determine the Safety and Efficacy of Hope Biosciences \\
& Autologous Mesenchymal Stem Cell Therapy (HB-adMSCs) to Provide Protection \\
& Against COVID-19 (NCT04349631) \\
Status: & Active, not recruiting (Phase II) \\
Treatment: & HB-adMSCs \\
\hline
\end{tabular}

\begin{tabular}{|c|c|}
\hline Study Name: & $\begin{array}{l}\text { Adipose Mesenchymal Cells for Abatement of SARS-CoV-2 Respiratory } \\
\text { Compromise in COVID-19 Disease (NCT04352803) }\end{array}$ \\
\hline Status: & Not yet recruiting(Phase I) \\
\hline Treatment: & Autologous Adipose MSC's \\
\hline Study Name: & Mesenchymal Stem Cells for the Treatment of COVID-19 (NCT04573270) \\
\hline Status: & Completed(Phase I) \\
\hline Treatment: & UC-MSC (PrimePro) \\
\hline
\end{tabular}

\begin{tabular}{|ll|}
\hline Study Name: & Novel Coronavirus Induced Severe Pneumonia Treated by Dental Pulp \\
& Mesenchymal Stem Cells (NCT04302519) \\
Status: & Not yet recruiting(Phase I) \\
Treatment: & Dental pulp MSC \\
\hline
\end{tabular}




\begin{tabular}{|ll|}
\hline Study Name: & Umbilical Cord Tissue (UC) Derived Mesenchymal Stem Cells (MSCs) Versus \\
& Placebo to Treat Acute Pulmonary Inflammation Due to COVID-19 \\
& (NCT04490486) \\
Status: & Not yet recruiting(Phase I) \\
Treatment: & UCMSCs \\
\hline
\end{tabular}

\begin{tabular}{|ll|}
\hline Study Name: & Use of UC-MSCs for COVID-19 Patients (NCT04355728) \\
Status: & Completed (Phase I,II) \\
Treatment: & Umbilical Cord Mesenchymal Stem Cells + Heparin along with best supportive \\
& care. \\
\hline
\end{tabular}

\begin{tabular}{|ll|}
\hline Study Name: & An Exploratory Study of ADR-001 in Patients With Severe Pneumonia Caused by \\
& SARS-CoV-2 Infection (NCT04522986) \\
Status: & Not yet recruiting (Phase I) \\
Treatment: & MSC \\
\hline
\end{tabular}

\begin{tabular}{|ll|}
\hline Study Name: & Treatment of Coronavirus COVID-19 Pneumonia (Pathogen SARS-CoV-2) With \\
& Cryopreserved Allogeneic P_MMSCs and UC-MMSCs (NCT04461925) \\
Status: & Recruiting (Phase I,II) \\
Treatment: & Placenta-Derived MMSCs; Cryopreserved Placenta-Derived Multipotent \\
& Mesenchymal Stromal Cells \\
\hline
\end{tabular}

\begin{tabular}{|ll|}
\hline Study Name: & Safety and Effectiveness of Mesenchymal Stem Cells in the Treatment of \\
& Pneumonia of Coronavirus Disease 2019 (NCT04371601) \\
Status: & Active, not recruiting (Phase I) \\
Treatment: & Oseltamivir mesenchymal stem cells \\
\hline
\end{tabular}

\begin{tabular}{|ll|}
\hline Study Name: & BAttLe Against COVID-19 Using MesenchYmal Stromal Cells (NCT04348461) \\
Status: & Not yet recruiting (Phase II) \\
Treatment: & Allogeneic and expanded adipose tissue-derived Mesenchymal stromal cells \\
\hline
\end{tabular}

\begin{tabular}{|ll|}
\hline Study Name: & Efficacy and Safety Study of Allogeneic HB-adMSCs for the Treatment of \\
& COVID-19 (NCT04362189) \\
Status: & Active, not recruiting (Phase II) \\
Treatment: & HB-adMSC \\
\hline
\end{tabular}

\begin{tabular}{|ll|}
\hline Study Name: & Therapeutic Study to Evaluate the Safety and Efficacy of DW-MSC in COVID-19 \\
& Patients (NCT04535856) \\
Status: & Completed(Phase I) \\
Treatment: & Allogeneic mesenchymal stem cell \\
\hline
\end{tabular}

\begin{tabular}{|ll|}
\hline Study Name: & Therapy for Pneumonia Patients ilnfected by 2019 Novel Coronavirus \\
& (NCT04293692) \\
Status: & Withdrawn \\
Treatment: & UC-MSCs \\
\hline
\end{tabular}

\begin{tabular}{|ll|}
\hline Study Name: & Safety and Efficacy of Intravenous Wharton's Jelly Derived Mesenchymal Stem \\
& Cells in Acute Respiratory Distress Syndrome Due to COVID 19 (NCT04390152) \\
Status: & Recruiting (Phase I,II) \\
Treatment: & WJ-MSC \\
\hline
\end{tabular}




\begin{tabular}{|ll|}
\hline Study Name: & Study of the Safety of Therapeutic Tx With Immunomodulatory MSC in Adults \\
& With COVID-19 Infection Requiring Mechanical Ventilation (NCT04397796) \\
Status: & Recruiting(Phase I) \\
Treatment: & BM-Allo.MSC \\
\hline
\end{tabular}

\begin{tabular}{|ll|}
\hline Study Name: & A Phase II Study in Patients With Moderate to Severe ARDS Due to COVID-19 \\
& (NCT04780685) \\
Status: & Recruiting (Phase II) \\
Treatment: & hMSC \\
\hline
\end{tabular}

\begin{tabular}{|ll|}
\hline Study Name: & Umbilical Cord Lining Stem Cells (ULSC) in Patients With COVID-19 ARDS \\
& (NCT04494386) \\
Status: & Recruiting (Phase I,II) \\
Treatment: & Umbilical Cord Lining Stem Cells (ULSC) \\
\hline
\end{tabular}

\begin{tabular}{|ll|}
\hline Study Name: & $\begin{array}{l}\text { Mesenchymal Stem Cells (MSCs) in Inflammation-Resolution Programs of } \\
\text { Coronavirus Disease 2019 (COVID-19) Induced Acute Respiratory Distress } \\
\end{array}$ \\
& Syndrome (ARDS) (NCT04377334) \\
Status: & Not yet recruiting (Phase II) \\
Treatment: & MSC \\
\hline
\end{tabular}

\begin{tabular}{|ll|}
\hline Study Name: & Use of hUC-MSC Product (BX-U001) for the Treatment of COVID-19 With \\
& ARDS (NCT04452097) \\
Status: & Not yet recruiting(Phase I,II) \\
Treatment: & Human umbilical cord mesenchymal stem cells \\
\hline
\end{tabular}

\begin{tabular}{|ll|}
\hline Study Name: & Mesenchymal Stromal Cells for the Treatment of SARS-CoV-2 Induced Acute \\
& Respiratory Failure (COVID-19 Disease) (NCT04345601) \\
Status: & Recruiting (Phase I,II) \\
Treatment: & Mesenchymal Stromal Cells \\
\hline
\end{tabular}

\begin{tabular}{|ll|}
\hline Study Name: & Efficacy and Safety Evaluation of Mesenchymal Stem Cells for the Treatment of \\
& Patients With Respiratory Distress Due to COVID-19 (NCT04390139) \\
Status: & Recruiting (Phase I,II) \\
Treatment: & Expanded MSC from Wharton Jelly (XCEL-UMC-BETA) \\
\hline
\end{tabular}

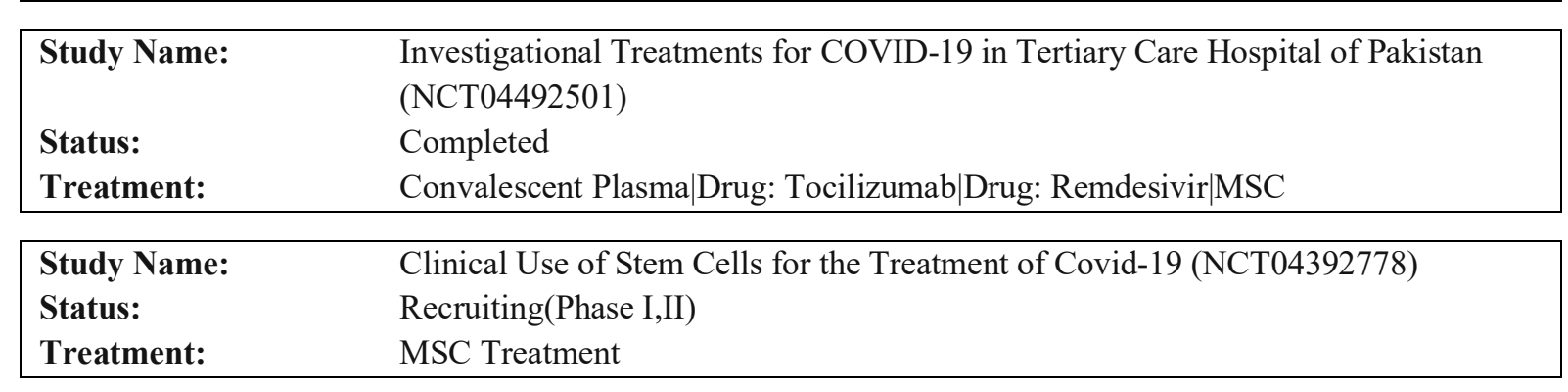

\begin{tabular}{|ll|}
\hline Study Name: & Safety and Feasibility of Allogenic MSC in the Treatment of COVID-19 \\
& (NCT04467047) \\
Status: & Not yet recruiting (Phase I) \\
Treatment: & Mesenchymal Stromal Cells infusion \\
\hline
\end{tabular}




\begin{tabular}{|ll|}
\hline Study Name: & The MEseNchymal coviD-19 Trial: a Pilot Study to Investigate Early Efficacy of \\
& MSCs in Adults With COVID-19 (NCT04537351) \\
Status: & Recruiting(Phase I,II) \\
Treatment: & Allogeneic mesenchymoangioblast-derived mesenchymal stem cells (MCA-derived \\
& MSCs)- (CYP-001) \\
\hline $\begin{array}{ll}\text { Study Name: } \\
\text { Status: }\end{array}$ & $\begin{array}{l}\text { ACT-20 in Patients With Severe COVID-19 Pneumonia (NCT04398303) } \\
\text { Treatment: }\end{array}$ \\
& $\begin{array}{l}\text { Allogenic human umbilical derived mesenchymal stem cells (ACT-20-MSC), Allo- } \\
\text { genic human umbilical derived mesenchymal stem cells in conditioned media } \\
\text { (ACT-20-CM) }\end{array}$ \\
\hline
\end{tabular}

\begin{tabular}{|ll|}
\hline Study Name: & Treatment of Severe COVID-19 Pneumonia With Allogeneic Mesenchymal \\
& Stromal Cells (COVID_MSV) (NCT04361942) \\
Status: & Recruiting (Phase II) \\
Treatment: & Mesenchymal Stromal Cells \\
\hline
\end{tabular}

\begin{tabular}{|ll|}
\hline Study Name: & $\begin{array}{l}\text { Repair of Acute Respiratory Distress Syndrome by Stromal Cell Administration } \\
\text { (REALIST) (COVID-19) (NCT03042143) }\end{array}$ \\
Status: & Recruiting(Phase I,II) \\
Treatment: & Human umbilical cord derived CD362 enriched MSCs \\
\hline
\end{tabular}

\begin{tabular}{|ll|}
\hline Study Name: & Umbilical Cord(UC)-Derived Mesenchymal Stem Cells(MSCs) Treatment for the \\
& 2019-novel Coronavirus(nCOV) Pneumonia (NCT04269525) \\
Status: & Recruiting(Phase II) \\
Treatment: & UC-MSCs \\
\hline
\end{tabular}

\begin{tabular}{|ll|}
\hline Study Name: & Mesenchymal Stromal Cell Therapy For The Treatment Of Acute Respiratory \\
& Distress Syndrome (NCT04447833) \\
Status: & Active, not recruiting(Phase I) \\
Treatment: & Mesenchymal Stromal Stem Cells - KI-MSC-PL-205 \\
\hline
\end{tabular}

\begin{tabular}{|ll|}
\hline Study Name: & Efficacy of Intravenous Infusions of Stem Cells in the Treatment of COVID-19 \\
& Patients (NCT04437823) \\
Status: & Recruiting(Phase II) \\
Treatment: & Intravenous Infusions of Stem Cells \\
\hline
\end{tabular}

\begin{tabular}{|ll|}
\hline Study Name: & $\begin{array}{l}\text { Safety and Efficiency of Method of Exosome Inhalation in COVID-19 Associated } \\
\text { Pneumonia (NCT04602442) }\end{array}$ \\
Status: & Enrolling by invitation(Phase II) \\
Treatment: & Exosome inhalation (EXO 1 inhalation) (EXO 2 inhalation) \\
\hline
\end{tabular}

\begin{tabular}{ll|}
\hline Study Name: & $\begin{array}{l}\text { Evaluation of Safety and Efficiency of Method of Exosome Inhalation in SARS- } \\
\text { CoV-2 Associated Pneumonia. (NCT04491240) } \\
\text { Completed(Phase I,II) }\end{array}$ \\
Status: & Exosome inhalation (EXO 1 inhalation)| (EXO 2 inhalation) \\
Treatment: & Cell Therapy Using Umbilical Cord-derived Mesenchymal Stromal Cells in SARS- \\
\hline Study Name: & CoV-2-related ARDS (NCT04333368) \\
& Active, not recruiting(Phase I,II) \\
Status: & Umbilical cord Wharton's jelly-derived human Mesenchymal Stromal Cells \\
Treatment: &
\end{tabular}




\begin{tabular}{|ll|}
\hline Study Name: & MSCs in COVID-19 ARDS (NCT04371393) \\
Status: & Active, not recruiting (Phase III) \\
Treatment: & Expanded mesenchymal stromal cells derived from the bone \\
& marrow (Remestemcel-L) \\
\hline
\end{tabular}

\begin{tabular}{|ll|}
\hline Study Name: & Study of Descartes-30 in Acute Respiratory Distress Syndrome (NCT04524962) \\
Status: & Recruiting(Phase I,II) \\
Treatment: & RNA-engineered off-the-shelf allogeneic mesenchymal stem cell MSC (Descartes \\
& $30)$ \\
\hline
\end{tabular}

\begin{tabular}{|ll|}
\hline Study Name: & Multiple Dosing of Mesenchymal Stromal Cells in Patients With ARDS (COVID- \\
& 19) (NCT04466098) \\
Status: & Recruiting(Phase II) \\
Treatment: & Mesenchymal stromal cells \\
\hline
\end{tabular}

\begin{tabular}{|ll|}
\hline Study Name: & Cellular Immuno-Therapy for COVID-19 Acute Respiratory Distress Syndrome - \\
& Vanguard (NCT04400032) \\
Status: & Recruiting(Phase I) \\
Treatment: & Mesenchymal Stromal Cells \\
\hline
\end{tabular}

\begin{tabular}{|ll|}
\hline Study Name: & A Pilot Clinical Study on Inhalation of Mesenchymal Stem Cells Exosomes \\
& Treating Severe Novel Coronavirus Pneumonia (NCT04276987) \\
Status: & Completed(Phase I) \\
Treatment: & MSCs-derived exosomes \\
\hline
\end{tabular}

\begin{tabular}{|ll|}
\hline Study Name: & $\begin{array}{l}\text { Mesenchymal Stem Cells for the Treatment of Various Chronic and Acute } \\
\text { Conditions (NCT04684602) }\end{array}$ \\
Status: & Recruiting(Phase I,II) \\
Treatment: & Human umbilical chord tissue-derived MSC (PrimePro \\
\hline
\end{tabular}

*data from ClinicalTrials.gov searched on March 6th 2021.

\section{Future directions}

Other clinical trials also accentuate the significance and safety of MSCs usage in the treatment of COVID-19 patients with no reporting of any serious adverse events related to MSCs (92-100), although there is a necessity for large randomized multicenter clinical trials in order to determine precise therapeutic potentials of MSC in COVID-19-induced disease $(92,93,97)$. It is also very important to emphasize that MSCs should not be administered in the early period of viral infection because inflammation is very pertinent and advantageous to combat viral infection. "Physiological inflammation" which is very important for control of virus infection and replication, can be abrogated by too much immunosuppression that is induced by inadequate use of MSCs in terms of the time of MSCs administration and their dose (101-104). However, there is the urge to investigate the safety of using human MSCs in long period follow- up. It is well- known that MSCs exhibit potential risks of adverse events during MSC transplantation (105) in CVDs (cardiovascular disease), neurological disease, GVHD (graft- versus host disease), and orthopedics, such as pro-tumorigenic effect, perturbed differentiation capacity, short surviving after implantation, not so amazing improvements, immune response and infection- related mortality (106). Some animal studies reported that MSCs therapy for CVDs can exhibit some adverse events such as proarrhythmic (107) and tumorigenic ability in heart tissue (108) as well as the ability to differentiate into unwanted tissue type (109). Although many studies suggest the usage of MSCs as a treatment in orthopedics, it is important to note that MSCs are able to take part in ectopically forming bone tissue in non-bone tissues, which is better known as heterotopic ossification (HO) (110). Although MSCs are cells with doubtful- advantage in numerous animal studies that showed MSCs promoted tumor growth and metastasis $(111,112)$, or even suppressed their growth (112), MSCs should be used with caution in clinical studies.

\section{CONCLUSION}

All of the effects from MSCs in regards to immune system, regeneration, neoangiogenesis, antiviral capacity, ubiquitous presence in almost all postnatal tissues and ease of transplantation make MSCs potentially excellent choice against Covid-19. However, MSCs therapy is a double edged sword, and if not applied correctly and responsibly can worsen clinical condition of patients and lead to adverse 
effect. So, in spite the data from small number of completed clinical trials that displayed MSCs therapy as safe and beneficial and on the other hand, dozens of ongoing clinical trials, final conclusion is yet to be brought.

\section{CONFLICT OF INTEREST}

The authors declare that they have no conflict of interest.

\section{ACKNOWLEDGEMENT}

This study was supported by the Ministry of Education, Science and Technological Development of the Republic of Serbia (175103), MP 01/18 and JP 25/19.

\section{LITERATURE}

1. Volarevic V, Ljujic B, Stojkovic P, Lukic A, Arsenijevic $\mathrm{N}$, Stojkovic M. Human stem cell research and regenerative medicine--present and future. $\mathrm{Br}$ Med Bull. 2011;99:155-68.

2. Dominici M, Le Blanc K, Mueller I, et al. Minimal criteria for defining multipotent mesenchymal stromal cells. The International Society for Cellular Therapy position statement. Cytotherapy. 2006;8(4):315-7.

3. Volarevic V, Nurkovic J, Arsenijevic N, Stojkovic M. Concise review: Therapeutic potential of mesenchymal stem cells for the treatment of acute liver failure and cirrhosis. Stem Cells. 2014;32(11):2818-23.

4. Volarevic V, Al-Qahtani A, Arsenijevic N, Pajovic S, Lukic ML. Interleukin-1 receptor antagonist (IL-1Ra) and IL-1Ra producing mesenchymal stem cells as modulators of diabetogenesis. Autoimmunity. 2010;43(4):255-63.

5. Djouad F, Charbonnier LM, Bouffi C, Louis-Plence P, et al. Mesenchymal stem cells inhibit the differentiation of dendritic cells through an interleukin-6-dependent mechanism. Stem Cells. 2007;25(8):2025-32.

6. Aggarwal S, Pittenger MF. Human mesenchymal stem cells modulate allogeneic immune cell responses. Blood. 2005;105(4):1815-22.

7. Beyth S, Borovsky Z, Mevorach D, et al. Human mesenchymal stem cells alter antigen-presenting cell maturation and induce T-cell unresponsiveness. Blood. 2005;105(5):2214-9.

8. Chamberlain G, Fox J, Ashton B, Middleton J. Concise review: mesenchymal stem cells: their phenotype, differentiation capacity, immunological features, and potential for homing. Stem Cells. 2007;25(11):2739-49.

9. Gazdic M, Volarevic V, Arsenijevic N, Stojkovic M. Mesenchymal stem cells: a friend or foe in immune-mediated diseases. Stem Cell Rev Rep. 2015;11(2):280-7.

10. Waterman RS, Tomchuck SL, Henkle SL, Betancourt AM. A new mesenchymal stem cell (MSC) paradigm: polarization into a pro-inflammatory $\mathrm{MSC} 1$ or an Immunosuppressive MSC2 phenotype. PLoS One. 2010;5(4):e10088.
11. Shi Y, Wang Y, Li Q, et al. Immunoregulatory mechanisms of mesenchymal stem and stromal cells in inflammatory diseases. Nat Rev Nephrol. 2018;14(8):493-507.

12. Romieu-Mourez R, François M, Boivin MN, Bouchentouf M, Spaner DE, Galipeau J. Cytokine modulation of TLR expression and activation in mesenchymal stromal cells leads to a proinflammatory phenotype. J Immunol. 2009;182(12):7963-73.

13. Ma S, Xie N, Li W, Yuan B, Shi Y, Wang Y. Immunobiology of mesenchymal stem cells. Cell Death Differ. 2014;21(2):216-25.

14. Harrell CR, Jovicic N, Djonov V, Volarevic V. Therapeutic Use of Mesenchymal Stem Cell-Derived Exosomes: From Basic Science to Clinics. Pharmaceutics. 2020;12(5):474.

15. Harrell CR, Miloradovic D, Sadikot R, et al. Molecular and Cellular Mechanisms Responsible for Beneficial Effects of Mesenchymal Stem Cell-Derived Product "Exod-MAPPS" in Attenuation of Chronic Airway Inflammation. Anal Cell Pathol (Amst). 2020;2020:3153891.

16. Colombo M, Raposo G, Théry C. Biogenesis, secretion, and intercellular interactions of exosomes and other extracellular vesicles. Annu Rev Cell Dev Biol. 2014;30:255-89.

17. Ferreira JR, Teixeira GQ, Santos SG, Barbosa MA, Almeida-Porada G, Gonçalves RM. Mesenchymal Stromal Cell Secretome: Influencing Therapeutic Potential by Cellular Pre-conditioning. Front Immunol. 2018;9:2837.

18. Kaur S, Abu-Shahba AG, Paananen RO, et al. Small non-coding RNA landscape of extracellular vesicles from human stem cells. Sci Rep. 2018;8(1):15503.

19. Whiteside TL. Exosome and mesenchymal stem cell cross-talk in the tumor microenvironment. Semin Immunol. 2018;35:69-79.

20. Androulidaki A, Iliopoulos D, Arranz A, et al. The kinase Akt1 controls macrophage response to lipopolysaccharide by regulating microRNAs. Immunity. 2009;31(2):220-231.

21. Kumar M, Ahmad T, Sharma A, Mabalirajan U, Kulshreshtha A, Agrawal A, Ghosh B. Let-7 microRNA-mediated regulation of IL-13 and allergic airway inflammation. $\mathrm{J}$ Allergy Clin Immunol. 2011;128(5):1077-85.e1-10.

22. Schulte LN, Eulalio A, Mollenkopf HJ, Reinhardt R, Vogel J. Analysis of the host microRNA response to Salmonella uncovers the control of major cytokines by the let-7 family. EMBO J. 2011;30(10):1977-89.

23. Yang, L., Boldin, M. P., Yu, Y., Liu, C. S., Ea, C. K., Ramakrishnan, P., et al. . miR-146a controls the resolution of T cell responses in mice. Journal of Experimental Medicine. 2012; 209(9), 1655-1670.

24. Hart, M., Walch-Rückheim, B., Friedmann, K, S., Rheinheimer, S., Tänzer, T., Glombitza, B., ... Meese, E. miR-34a: A new player in the regulation of $\mathrm{T}$ cell function by modulation of NF- $\mathrm{B}$ signaling. Cell Death and Disease. 2019;10(2):46

25. Hillman, Y., Mazkereth, N., Farberov, L., Shomron, N., \& Fishelson, Z. Regulation of complement-dependent cytotoxicity by MicroRNAs miR-200b, miR-200c, and 
miR-217. The Journal of Immunology. 2016;196(12), 5156-5165.

26. Kehl D, Generali M, Mallone A, Heller M, Uldry AC, Cheng P, Gantenbein B, Hoerstrup SP, Weber B. Proteomic analysis of human mesenchymal stromal cell secretomes: a systematic comparison of the angiogenic potential. NPJ Regen Med. 2019;4:8

27. Kong P, Xie X, Li F, Liu Y, Lu Y. Placenta mesenchymal stem cell accelerates wound healing by enhancing angiogenesis in diabetic Goto-Kakizaki (GK) rats. Biochem Biophys Res Commun. 2013;438(2):410-9.

28. Bai L, Li D, Li J, et al. Bioactive molecules derived from umbilical cord mesenchymal stem cells. Acta Histochem. 2016;118(8):761-769.

29. Tao H, Han Z, Han ZC, Li Z. Proangiogenic Features of Mesenchymal Stem Cells and Their Therapeutic Applications. Stem Cells Int. 2016; 1314709.

30. Corliss BA, Azimi MS, Munson JM, Peirce SM, Murfee WL. Macrophages: An Inflammatory Link Between Angiogenesis and Lymphangiogenesis. Microcirculation. 2016;23(2):95-121.

31. Motegi SI, Ishikawa O. Mesenchymal stem cells: The roles and functions in cutaneous wound healing and tumor growth. J Dermatol Sci. 2017;86(2):83-89.

32. Harrell CR, Fellabaum C, Jovicic N, Djonov V, Arsenijevic N, Volarevic V. Molecular Mechanisms Responsible for Therapeutic Potential of Mesenchymal Stem Cell-Derived Secretome. Cells. 2019;8(5):467.

33. Stenderup, K., Justesen, J., Clausen, C., and Kassem, M. Aging is associated with decreased maximal life span and accelerated senescence of bone marrow stromal cells. Bone. 2003; 33, 919-926.

34. Lu LL, Liu YJ, Yang SG, et al. Isolation and characterization of human umbilical cord mesenchymal stem cells with hematopoiesis-supportive function and other potentials. Haematologica. 2006;91(8):1017-26.

35. Zuk PA, Zhu M, Ashjian P, et al. Human adipose tissue is a source of multipotent stem cells. Mol Biol Cell. 2002;13(12):4279-95.

36. Jin HJ, Bae YK, Kim M, et al. Comparative analysis of human mesenchymal stem cells from bone marrow, adipose tissue, and umbilical cord blood as sources of cell therapy. Int J Mol Sci. 2013;14(9):17986-8001.

37. Kern S, Eichler H, Stoeve J, Klüter H, Bieback K. Comparative analysis of mesenchymal stem cells from bone marrow, umbilical cord blood, or adipose tissue. Stem Cells. 2006 ;24(5):1294-301.

38. Markovic BS, Kanjevac T, Harrell CR, et al. Molecular and Cellular Mechanisms Involved in Mesenchymal Stem Cell-Based Therapy of Inflammatory Bowel Diseases. Stem Cell Rev. 2018;14(2):153-165

39. Harrell CR, Gazdic M, Fellabaum C, et al. Therapeutic Potential of Amniotic Fluid Derived Mesenchymal Stem Cells Based on their Differentiation Capacity and Immunomodulatory Properties. Curr Stem Cell Res Ther. 2019; 14: 327-336.

40. Chamberlain G, Fox J, Ashton B, Middleton J. Concise review: mesenchymal stem cells: their phenotype, differentiation capacity, immunological features, and potential for homing. Stem Cells. 2007;25(11):27392749.

41. Xie XH, Wang XL, He YX, et al. Promotion of bone repair by implantation of cryopreserved bone marrow-derived mononuclear cells in a rabbit model of steroid-associated osteonecrosis. Arthritis Rheum. 2012;64(5):1562-1571.

42. Mueller SM, Glowacki J. Age-related decline in the osteogenic potential of human bone marrow cells cultured in three-dimensional collagen sponges. J Cell Biochem. 2001;82(4):583-590.

43. Stenderup K, Justesen J, Clausen C, Kassem M. Aging is associated with decreased maximal life span and accelerated senescence of bone marrow stromal cells. Bone. 2003;33(6):919-926

44. Lu LL, Liu YJ, Yang SG, et al. Isolation and characterization of human umbilical cord mesenchymal stem cells with hematopoiesis-supportive function and other potentials. Haematologica. 2006;91(8):1017-1026

45. Zuk PA, Zhu M, Ashjian P, et al. Human adipose tissue is a source of multipotent stem cells. Mol Biol Cell. 2002;13(12):4279-4295.

46. Desterke C, Griscelli F, Imeri J, et al. Molecular investigation of adequate sources of mesenchymal stem cells for cell therapy of COVID-19-associated organ failure. Stem Cells Transl Med. 2020; 25:10.1002/sctm.200189.

47. Zhou P, Yang XL, Wang XG, et al. A pneumonia outbreak associated with a new coronavirus of probable bat origin. Nature. 2020;579(7798):270-273.

48. Huang C, Wang Y, Li X, et al. Clinical features of patients infected with 2019 novel coronavirus in Wuhan, China. Lancet. 2020;395(10223):497-506.

49. Li Q, Guan X, Wu P, et al. Early Transmission Dynamics in Wuhan, China, of Novel Coronavirus-Infected Pneumonia. N Engl J Med. 2020;382(13):1199-1207.

50. Rajarshi K, Chatterjee A, Ray S. Combating COVID-19 with mesenchymal stem cell therapy. Biotechnol Rep (Amst). 2020;26:e00467.

51. Wang J, Jiang M, Chen X, Montaner LJ. Cytokine storm and leukocyte changes in mild versus severe SARSCoV-2 infection: Review of 3939 COVID-19 patients in China and emerging pathogenesis and therapy concepts. J Leukoc Biol. 2020;108(1):17-41.

52. Gupta KK, Khan MA, Singh SK. Constitutive Inflammatory Cytokine Storm: A Major Threat to Human Health. J Interferon Cytokine Res. 2020;40(1):19-23.

53. Hu B, Huang S, Yin L. The cytokine storm and COVID19. J Med Virol. 2021;93(1):250-256.

54. Hussman JP. Cellular and Molecular Pathways of COVID-19 and Potential Points of Therapeutic Intervention. Front Pharmacol. 2020;11:1169.

55. Zhou Y, Fu B, Zheng X, et al. Aberrant pathogenic GM$\mathrm{CSF}+\mathrm{T}$ cells and inflammatory CD14+CD16+ monocytes in severe pulmonary syndrome patients of a new coronavirus. bioRxiv. 2020; 
56. Eguchi S, Kawai T, Scalia R, Rizzo V. Understanding Angiotensin II Type 1 Receptor Signaling in Vascular Pathophysiology. Hypertension. 2018;71(5):804-810.

57. Murakami M, Kamimura D, Hirano T. Pleiotropy and Specificity: Insights from the Interleukin 6 Family of Cytokines. Immunity. 2019;50(4):812-831.

58. Wong CK, Lam CW, Wu AK, et al. Plasma inflammatory cytokines and chemokines in severe acute respiratory syndrome. Clin Exp Immunol. 2004;136(1):95-103

59. Chen $\mathrm{G}, \mathrm{Wu} \mathrm{D}$, Guo W, et al. Clinical and immunological features of severe and moderate coronavirus disease 2019. J Clin Invest. 2020;130(5):2620-2629.

60. Liu J, Li S, Liu J, et al. Longitudinal characteristics of lymphocyte responses and cytokine profiles in the peripheral blood of SARS-CoV-2 infected patients. EBioMedicine. 2020;55:102763.

61. Xu Z, Shi L, Wang Y, et al. Pathological findings of COVID-19 associated with acute respiratory distress syndrome. Lancet Respir Med. 2020;8(4):420-422.

62. Ware LB, Matthay MA. The acute respiratory distress syndrome. N Engl J Med. 2000;342(18):1334-49.

63. Grasselli G, Zangrillo A, Zanella A, et al. Baseline characteristics and outcomes of 1591 patients infected with SARS-CoV-2 admitted to ICUs of the lombardy Region, Italy. JAMA 2020;323(16):1574.

64. Zhou F, Yu T, Du R, et al. Clinical course and risk factors for mortality of adult inpatients with COVID-19 in Wuhan, China: a retrospective cohort study. The Lancet. 2020;395:1054-62.

65. McGonagle D, Sharif K, O'Regan A, Bridgewood C. The Role of Cytokines including Interleukin-6 in COVID-19 induced Pneumonia and Macrophage Activation Syndrome-Like Disease. Autoimmun Rev. 2020;19(6):102537.

66. Bradford E, Jacobson S, Varasteh J, et al. The value of blood cytokines and chemokines in assessing COPD. Respir Res 2017;18(1).

67. Potere N, Di Nisio M, Cibelli D, et al. Interleukin-6 receptor blockade with subcutaneous tocilizumab in severe COVID-19 pneumonia and hyperinflammation: a case-control study. Ann Rheum Dis. 2021;80(2):1-2.

68. Khoury M, Cuenca J, Cruz FF, et al. Current status of cell-based therapies for respiratory virus infections: applicability to COVID-19. Eur Respir J. 2020;55(6):2000858.

69. Bailey CC, Zhong G, Huang IC, Farzan M. IFITMFamily Proteins: The Cell's First Line of Antiviral Defense. Annu Rev Virol. 2014;1:261-283.

70. Schoggins JW. Interferon-Stimulated Genes: What Do They All Do? Annu Rev Virol. 2019;6(1):567-584.

71. Kane M, Zang TM, Rihn SJ, et al. Identification of Interferon-Stimulated Genes with Antiretroviral Activity. Cell Host Microbe. 2016;20(3):392-405.

72. Sveiven SN, Nordgren TM. Lung-resident mesenchymal stromal cells are tissue-specific regulators of lung homeostasis. Am J Physiol Lung Cell Mol Physiol. 2020;319(2):L197-L210.

73. Rolandsson Enes S, Åhrman E, Palani A, Hallgren O, Bjermer L, Malmström A, Scheding S, Malmström J,
Westergren-Thorsson G. Quantitative proteomic characterization of lung-MSC and bone marrow-MSC using DIA-mass spectrometry. Sci Rep. 2017;7(1):9316.

74. Sinclair, K., Yerkovich, S. T., \& Chambers, D. C. . Mesenchymal stem cells and the lung. Respirology. 2013; 18(3):397-411.

75. Foronjy RF, Majka SM. The potential for resident lung mesenchymal stem cells to promote functional tissue regeneration: understanding microenvironmental cues. Cells. 2012;1(4):874.

76. Luo XY, Meng XJ, Cao DC, et al. Transplantation of bone marrow mesenchymal stromal cells attenuates liver fibrosis in mice by regulating macrophage subtypes. Stem Cell Res Ther. 2019;10(1):16.

77. Wang J, Wang BJ, Yang JC, et al. [Research advances in the mechanism of pulmonary fibrosis induced by coronavirus disease 2019 and the corresponding therapeutic measures]. Zhonghua Shao Shang Za Zhi. 2020;36(8):691-697.

78. Walter J, Ware LB, Matthay MA. Mesenchymal stem cells: mechanisms of potential therapeutic benefit in ARDS and sepsis. Lancet Respir Med. 2014;2(12):101626.

79. Atluri S, Manchikanti L, Hirsch JA. Expanded Umbilical Cord Mesenchymal Stem Cells (UC-MSCs) as a Therapeutic Strategy in Managing Critically Ill COVID19 Patients: The Case for Compassionate Use. Pain Physician. 2020;23(2):E71-E83.

80. Leng Z, Zhu R, Hou W, et al. Transplantation of ACE2- Mesenchymal Stem Cells Improves the Outcome of Patients with COVID-19 Pneumonia. Aging Dis. 2020;11(2):216-228.

81. McIntyre LA, Moher D, Fergusson DA, et al. Efficacy of Mesenchymal Stromal Cell Therapy for Acute Lung Injury in Preclinical Animal Models: A Systematic Review. PLoS One. 2016;11(1):e0147170.

82. Behnke J, Kremer S, Shahzad T, et al. MSC Based Therapies-New Perspectives for the Injured Lung. J Clin Med. 2020;9(3):682.

83. Majolo F, da Silva GL, Vieira L, Timmers LFSM, Laufer S, Goettert MI. Review of Trials Currently Testing Stem Cells for Treatment of Respiratory Diseases: Facts Known to Date and Possible Applications to COVID-19. Stem Cell Rev Rep. 2021;17(1):44-55.

84. Wilson JG, Liu KD, Zhuo H, et al. Mesenchymal stem (stromal) cells for treatment of ARDS: a phase 1 clinical trial. Lancet Respir Med. 2015;3(1):24-32.

85. Matthay MA, Calfee CS, Zhuo H, et al. Treatment with allogeneic mesenchymal stromal cells for moderate to severe acute respiratory distress syndrome (START study): a randomised phase 2a safety trial. Lancet Respir Med. 2019;7(2):154-162.

86. Harrell CR, Sadikot R, Pascual J, et al. Mesenchymal Stem Cell-Based Therapy of Inflammatory Lung Diseases: Current Understanding and Future Perspectives. Stem Cells Int. 2019;2019:4236973.

87. Liu S, Peng D, Qiu H, Yang K, Fu Z, Zou L. Mesenchymal stem cells as a potential therapy for COVID-19. Stem Cell Res Ther. 2020;11(1):169. 
88. Rajarshi K, Chatterjee A, Ray S. Combating COVID-19 with mesenchymal stem cell therapy. Biotechnol Rep (Amst). 2020;26:e00467.

89. Zhang Y, Ding J, Ren S, et al. Intravenous infusion of human umbilical cord Wharton's jelly-derived mesenchymal stem cells as a potential treatment for patients with COVID-19 pneumonia. Stem Cell Res Ther. 2020;11(1):207.

90. Golchin A, Seyedjafari E, Ardeshirylajimi A. Mesenchymal Stem Cell Therapy for COVID-19: Present or Future. Stem Cell Rev Rep. 2020;16(3):427-433.

91. Sengupta V, Sengupta S, Lazo A, Woods P, Nolan A, Bremer N. Exosomes Derived from Bone Marrow Mesenchymal Stem Cells as Treatment for Severe COVID19. Stem Cells Dev. 2020;29(12):747-754.

92. Hashemian SR, Aliannejad R, Zarrabi M, et al. Mesenchymal stem cells derived from perinatal tissues for treatment of critically ill COVID-19-induced ARDS patients: a case series. Stem Cell Res Ther. 2021;12(1):91

93. Gorman E, Shankar-Hari M, Hopkins P, et al. Repair of Acute Respiratory Distress Syndrome by Stromal Cell Administration in COVID-19 (REALIST-COVID-19): A structured summary of a study protocol for a randomised, controlled trial. Trials. 2020;21(1):462

94. Xu X, Jiang W, Chen L, et al. Evaluation of the safety and efficacy of using human menstrual blood-derived mesenchymal stromal cells in treating severe and critically ill COVID-19 patients: An exploratory clinical trial. Clin Transl Med. 2021;11(2):e297.

95. Liang B, Chen J, Li T, et al. Clinical remission of a critically ill COVID-19 patient treated by human umbilical cord mesenchymal stem cells: A case report. Medicine (Baltimore). 2020;99(31):e21429.

96. Leng Z, Zhu R, Hou W, et al. Transplantation of ACE2- Mesenchymal Stem Cells Improves the Outcome of Patients with COVID-19 Pneumonia. Aging Dis. 2020;11(2):216-228.

97. Chen Y, Zhang Q, Peng W, et al. Efficacy and safety of mesenchymal stem cells for the treatment of patients infected with COVID-19: a systematic review and metaanalysis protocol. BMJ Open. 2020;10(12):e042085.

98. Sánchez-Guijo F, García-Arranz M, López-Parra M, et al. Adipose-derived mesenchymal stromal cells for the treatment of patients with severe SARS-CoV-2 pneumonia requiring mechanical ventilation. A proof of concept study. EClinicalMedicine. 2020;25:100454.

99. Lanzoni G, Linetsky E, Correa D, et al. Umbilical cord mesenchymal stem cells for COVID-19 acute respiratory distress syndrome: A double-blind, phase 1/2a, randomized controlled trial. Stem Cells Transl Med. 2021.

100.Qu W, Wang Z, Hare JM, et al. Cell-based therapy to reduce mortality from COVID-19: Systematic review and meta-analysis of human studies on acute respiratory distress syndrome. Stem Cells Transl Med. 2020;9(9):1007-1022.

101.Golchin A, Seyedjafari E, Ardeshirylajimi A. Mesenchymal Stem Cell Therapy for COVID-19: Present or Future. Stem Cell Rev Rep. 2020;16(3):427-433.
102. Khoury M, Cuenca J, Cruz FF, Figueroa FE, Rocco PRM, Weiss DJ. Current status of cell-based therapies for respiratory virus infections: applicability to COVID19. Eur Respir J. 2020;55(6):2000858.

103. Yu F, Jia R, Tang Y, Liu J, Wei B. SARS-CoV-2 infection and stem cells: Interaction and intervention. Stem Cell Res. 2020;46:101859.

104.Zumla A, Wang FS, Ippolito G, et al. Reducing mortality and morbidity in patients with severe COVID-19 disease by advancing ongoing trials of Mesenchymal Stromal (stem) Cell (MSC) therapy - Achieving global consensus and visibility for cellular host-directed therapies. Int $\mathrm{J}$ Infect Dis. 2020;96:431-439.

105.Lukomska B, Stanaszek L, Zuba-Surma E, Legosz P, Sarzynska S, Drela K. Challenges and Controversies in Human Mesenchymal Stem Cell Therapy. Stem Cells Int. 2019; 2019:9628536.

106.von Bahr L, Sundberg B, Lönnies L, et al. Long-term complications, immunologic effects, and role of passage for outcome in mesenchymal stromal cell therapy. Biol Blood Marrow Transplant. 2012;18(4):557-64.

107.Price MJ, Chou CC, Frantzen M, et al. Intravenous mesenchymal stem cell therapy early after reperfused acute myocardial infarction improves left ventricular function and alters electrophysiologic properties. Int J Cardiol. 2006;111(2):231-9.

108.Jeong JO, Han JW, Kim JM, et al. Malignant tumor formation after transplantation of short-term cultured bone marrow mesenchymal stem cells in experimental myocardial infarction and diabetic neuropathy. Circ Res. 2011;108(11):1340-7.

109. Breitbach M, Bostani T, Roell W, et al. Potential risks of bone marrow cell transplantation into infarcted hearts. Blood. 2007;110(4):1362-9.

110. Kan C, Chen L, Hu Y, et al. Microenvironmental factors that regulate mesenchymal stem cells: lessons learned from the study of heterotopic ossification. Histol Histopathol. 2017;32(10):977-985.

111.Ljujic B, Milovanovic M, Volarevic V, et al. Human mesenchymal stem cells creating an immunosuppressive environment and promote breast cancer in mice. Sci Rep. 2013;3:2298.

112. Miloradovic D, Miloradovic D, Markovic BS, et al. The Effects of Mesenchymal Stem Cells on Antimelanoma Immunity Depend on the Timing of Their Administration. Stem Cells Int. 2020;2020:8842659. 